\title{
Representatividad y afiliación en el movimiento sindical español ${ }^{1}$
}

\author{
Obdulia Taboadela \\ Universidad de La Coruña
}

\section{Resumen}

El artículo repasa la historia reciente del movimiento sindical en España tomando como punto de referencia la evolución de las cifras de afiliación. Se trata de explicar la relación entre estrategias sindicales, situación de los trabajadores y variaciones en la tasa de afiliación.

Palabras clave: afiliación sindical, sindicalismo contemporáneo, representatividad, estrategias sindicales.

\section{Abstract. Representativity and affiliation in the spanish trade union movement}

The paper explains the recent history of trade union movement in Spain from the perspective of trade union membership. The article explores the relationship among trade union strategies, workers position and union density.

Key words: trade union affiliation, contemporary sindicalism, representativity, trade unions strategies.

Los años ochenta y noventa han supuesto, en la mayoría de los países europeos, un descenso generalizado de las tasas de afiliación sindical ${ }^{2}$. Tras años de crecimiento sostenido y mejoras para el movimiento sindical en estos países, uno de los efectos más visibles de la recesión económica ha sido no sólo la pérdida de efectivos sindicales, sino también un retroceso general en la institucionalización y el poder de los movimientos sindicales.

1. Este artículo es una exégesis revisada de una parte del trabajo que sobre afiliación sindical fue presentado como tesis doctoral. Para un análisis específico sobre cifras y distribución de la afiliación sindical derivadas de la investigación, pueden consultarse los artículos: BOUZA, F; TABOADELA, O: "La evolución de la afiliación sindical en España y la cultura histórica de los sindicatos». Documentación Social núm. 94, 1994, p. 119-127, y TABOADELA, O: "Clases sociales y acción colectiva». REIS, núm. 63, 1993, p. 71-97.

2. OCDE: Perspectives de l'emploi. París, OCDE, 1991. 
En este escenario de pérdida de influencia general del movimiento sindical europeo, el objeto del artículo es presentar un marco analítico general que explique la situación del movimiento sindical y la afiliación en España. Más en concreto, el estudio de la consolidación del movimiento sindical (en relación con la afiliación) en España tras el régimen autoritario franquista, así como sus oportunidades de desarrollo en un contexto de crisis económica, inestabilidad política y cambios estructurales de alcance mundial que han afectado a nuestro país durante el período de referencia: 1977-1991.

Después de quince años de sindicalismo democrático el resultado (en lo que a afiliación se refiere) ha sido las tasas más bajas de sindicación de los países europeos $^{3}$. La hipótesis central de partida es que tal situación se ha debido a la conjugación de aspectos atinentes al avance de las economías complejas, en lo que podría llamarse factores estructurales, junto a otros condicionantes relacionados con el desarrollo concreto de nuestro país. Ambos tipos de influencias han derivado en una situación que ha afectado negativamente tanto a la oportunidad de la afiliación como al grado de propensión de los trabajadores españoles hacia la organización sindical ${ }^{4}$.

Las consecuencias conocidas de la crisis sobre el mercado de trabajo, no sólo en términos de desempleo sino también como cambios ocupacionales, han sido en el caso español lo suficientemente rápidos y profundos como para afectar sensiblemente tanto a la capacidad de arbitrar intereses como a la cantidad de recursos para defenderlos. Hasta aquí el argumento se incardina en los cambios estructurales que han afectado a la mayor parte de las economías complejas. Pero además, en el caso español, el análisis de los bajos niveles de afiliación sindical ha de ser completado con otra clase de explicaciones. En particular, mantengo que una específica estrategia del movimiento sindical en España, tal cual es la tensión entre las dos facetas básicas de la acción sindical —sindicalismo solidario y sindicalismo de afiliación-, no ha permitido que los sindicatos españoles adecuaran sus niveles afiliativos al resto de los países del entorno. A su vez, tal tensión entre ambas lógicas, nombradas en la literatura internacional como lógica de la influencia (relaciones con los agentes sociales) y lógica de los miembros (relaciones con sus representados), responde a un genuino y condicionado desarrollo del movimiento sindical en nuestro país.

La afiliación sindical, como cualquier proceso social que se extiende a lo largo del tiempo, está sujeto a variaciones relacionadas con las transformaciones en

3. OCDE, ibídem.

4. Se parte del supuesto de que la decisión de la afiliación sindical por parte del trabajador está constreñida, al nivel más general, por dos tipos de factores: la propension, o la cantidad de intereses defendibles a través de la acción colectiva, y la oportunidad, definida por la capacidad para elegir la acción colectiva y la acción sindical como medio de defensa de esos recursos e intereses. 
los sistemas sociales de referencia. Si atendemos a la evolución de la afiliación sindical en los países europeos, una primera conclusión de gran utilidad analítica es que el periodo de intenso crecimiento afiliativo de la década de los setenta ha sido una excepción en el desarrollo general de los movimientos sindicales europeos. La tendencia en los últimos cincuenta años fue de crecimientos suaves; sólo a partir de los años setenta, y durante menos de una década, muchos países europeos vieron crecer sensiblemente sus tasas de afiliación. Ahora bien, tal extraordinario incremento en el número de efectivos sindicales puede considerarse más que la regla, algo excepcional, por cuanto supuso una ruptura en la tendencia de crecimientos leves que, con variaciones, se había iniciado alrededor de los años cuarenta. Parece entonces más lógico estudiar los años setenta como un hecho extraordinario más que como pauta evolutiva y secuencial. La última década se ha saldado con la caída de las tasas de afiliación que, en términos generales, se han situado en los niveles anteriores a la expansión de la década de los setenta ${ }^{5}$.

Desde esta perspectiva, cobra sentido la tesis por la cual los incrementos afiliativos de los años setenta fueron posibles gracias a un cúmulo apreciable de variables relacionadas positivamente con la afiliación sindical. Tomando en consideración la rapidez y la direccionalidad de las transformaciones recientes (de signo y consecuencias negativas para la afiliación sindical), es difícil que en el medio plazo se produzca un contexto tan favorable como lo fueron para la acción sindical los años sesenta y setenta: relativa homogeneidad del mercado de trabajo, pleno empleo, bonanza económica, Estado de bienestar, partidos socialdemócratas en el Gobierno, etc.

El proceso de reestructuración industrial y del mercado laboral junto a la crisis económica han modificado sensiblemente los escenarios productivos de las sociedades occidentales. Pero al contrario que en las pasadas décadas, tales cambios (tecnológicos, productivos y laborales) han erosionado los recursos para la acción colectiva. Todas las transformaciones apuntan en la misma dirección: la complejización, diversificación y heterogeneidad creciente de las sociedades de capitalismo avanzado. En estas condiciones, las posibilidades de la acción colectiva se reducen extraordinariamente. A la dificultad objetiva para aunar intereses diversos en el mundo del trabajo, se añaden las condiciones productivas que, por su propia naturaleza, estimulan la división y el recurso a la acción individual. La representación y la intermediación de intereses comunes, clave del éxito de la acción sindical en los sesenta y setenta, se convierte, a partir de la década de los años ochenta, en creciente dificultad para aglutinar la complejidad y la heterogeneidad de los intereses de la clase trabajadora.

Uno de los efectos más visibles de estos cambios en relación con la acción sindical, y más concretamente con la capacidad de las organizaciones para man-

5. VISSER, J.: «Trade unionism in Western Europe: Present situation and prospects". Labour and Society. Vol. 13, núm. 2, 1988, p. 125-182, y VISSER, J.: European Trade Unions in figures. Deventer, Kluwer Publ., 1989. 
tener a sus miembros, es la pérdida de la identidad de clase. La propia pérdida de centralidad de la clase obrera como una clase social ha desvanecido la percepción por parte de los trabajadores de la pertenencia a un agregado de individuos con características comunes, actitudes compartidas y objetivos universales.

E.O. Wright ${ }^{6}$ analiza las transformaciones en la estructura y en la conciencia de clase en las sociedades avanzadas. Según el autor, la conciencia de clase estaría dividida en dos dimensiones: la primera, de carácter afectivo, estaría construida a través de la ideología y orientada al pasado. La segunda dimensión, de carácter objetivo, tendría a los intereses racionales como característica definitoria, orientando la acción hacia el futuro. En una perspectiva más concreta que aquellos análisis que insisten en el declinar de las ideologías ${ }^{7}$, lo que se afirma es la progresiva importancia en las sociedades actuales de la dimensión racional de la conciencia de clase. La descomposición de las condiciones objetivas de homogeneidad tiene como correlato una más débil percepción de las semejanzas y un incremento paralelo de las diferencias. De aquí se deriva un cambio en la percepción de la acción colectiva. El concepto básico sobre el que pivotaba la conciencia de la clase trabajadora, la solidaridad, se transforma por mor de las condiciones objetivas de los trabajadores en un recurso más retórico que real. Los intereses dejan de ser intereses de clase para convertirse en intereses más dependientes de la situación específica de los individuos en la estructura ocupacional.

La puesta en escena de los intereses y la capacidad para actualizarlos en forma de recursos de acción colectiva quedan reducidos en un contexto definido por un proceso de individualización objetiva y subjetiva. La consecuencia son los crecientes obstáculos para la combinación de la lógica de acción colectiva y la individual. Sin el recurso a la apelación de valores solidarios y colectivos la construcción de intereses a defender mediante la acción sindical se complejiza de manera notable. La vinculación con la acción sindical y sus organizaciones ha de ser argumentada de acuerdo con nuevas premisas, toda vez que el elemento estructurador de la conciencia subjetiva es relativizado en la experiencia real de los trabajadores.

Si la afiliación sindical se relaciona con los intereses y la capacidad de defensa de los mismos mediante la acción colectiva o, en otros términos, con el grado de propensión y oportunidad en relación con la pertenencia a la organización sindical, las nuevas condiciones económicas, sociales y políticas derivadas de los últimos desarrollos en las sociedades complejas, relativizan y disminuyen ambas dimensiones de la afiliación; la propensión por cuanto la generación de intereses grupales se vuelve difícil por la segmentación y la diver-

6. WRIGHT, E.O. y KWANG-YEONG, S: "Temporality class structure and class consciousness: A comparative analysis of the effects of class trayectory and class structure on class consciousness in Sweden and the United Statess. Mimeo, Department of Sociology. Madison. University of Wisconsin, 1987.

7. BELL, D.: El fin de las ideologias. Madrid, Ministerio de Trabajo y Seguridad Social, 1992. 
sificación de las condiciones productivas de los trabajadores, y la oportunidad debido a las tendencias generales de preeminencia de las respuestas individuales en vez de las colectivas.

Este tipo de cambios estructurales ha sido común al desarrollo de las economías complejas y por tanto nuestro país, dentro del entorno capitalista, ha sufrido parecidas transformaciones. Pero además, la coincidencia en el tiempo de estos cambios con la transición política se resume en un singular proceso de desarrollo del movimiento sindical. La concurrencia de ambos factores, los generales y los particulares, muestra, por otra parte, interesantes claves de análisis para la comprensión de los bajos niveles de afiliación existentes en el sindicalismo español.

\section{III}

Crisis económica, cambio de régimen y legado franquista han sido señalados como elementos determinantes en la configuración de nuestro sistema de relaciones laborales. Tales variables, de amplia repercusión en la literatura de referencia, no por analizadas han perdido su poder explicativo. La tesis propuesta al comienzo de estas páginas, según la cual el especial entorno de la acción sindical en su etapa de consolidación habría marcado cierta determinación en las acciones y en el desenvolvimiento sindical en los años posteriores, cobra especial relevancia y significación después del análisis de los procesos afiliativos durante el período 1977-19918.

En las difíciles condiciones de un régimen autoritario, el movimiento sindical clandestino significaba, ante todo, oposición a la dictadura. La ausencia de libertades democráticas se constituía el eje vertebrador de cualquier movimiento de oposición al franquismo; las cuestiones laborales venían siempre referidas a la demanda de un sistema libre de relaciones industriales. Ahora bien, de aquí no puede concluirse que la mayoría de los españoles, en este caso los trabajadores, optaran por la solución radical de la oposición abierta y la combatividad contra el régimen. Más bien al contrario, la bonanza de la situación económica y el encuentro paulatino con Europa, conllevaron, si no cierta aquiescencia con la dictadura, sí cierta adaptación al entorno. De acuerdo con la tesis de Pérez Díaz ${ }^{9}$ según la cual al llegar a la transición la sociedad española había experimentado una evolución hacia una relativa sincronización con la vida, la cultura y las instituciones europeas, no es menos cierto que en relación con la acción colectiva su desarrollo estuvo condicionado por la etapa de dictadura y clandestinidad. Aunque la última década del franquismo se caracterizó por la apertura y la suavización de las condiciones políticas, derivadas a

8. Para un análisis detallado de la evolución de la afiliación en cifras ver: BOUZA, F.; TABOADela, O., ibídem, p. 1.

9. Pérez Diaz, V.: "La emergencia de la España democrática. La "invención" de una tradición y la dudosa institucionalización de una democracia" Claves de Razón Práctica, núm. 13, 1991, p. 63. 
su vez de los cambios económicos y culturales experimentados por la sociedad civil en la década de los sesenta, en lo atinente a la acción sindical la inexistencia de un sistema de relaciones industriales democrático influyó decisivamente en el modelo sindical desarrollado a través de la transición.

El movimiento sindical durante el franquismo fue un movimiento de oposición política al régimen; las movilizaciones, la negociación y las tácticas de las organizaciones sindicales clandestinas estaban referidas a la demanda de libertades políticas, eje sobre el que pivotaba cualquier reforma más específica en el centro de trabajo. Al contrario que los trabajadores europeos, acostumbrados a unas organizaciones sindicales instaladas en el ámbito de lo público, pero con unas funciones y unas demandas acotadas en el terreno laboral, el trabajador español de los últimos años del franquismo se acostumbró a la percepción de un movimiento sindical atravesado por lo político y movilizado fundamentalmente por la idea de oposición política al régimen. Tal estrategia sindical, perfectamente coherente con el contexto interno del país (no podían reformarse radicalmente las condiciones en el centro de trabajo sin un marco más amplio de libertades democráticas), tuvo importantes consecuencias, tanto para el diseño posterior de las organizaciones sindicales cuanto para la imagen y la percepción del movimiento sindical por parte de los trabajadores.

Las buenas condiciones económicas del país derivadas del crecimiento de los años sesenta, la excesiva tutela de un Estado interventor y paternalista en las relaciones de trabajo, el intercambio implícito de la seguridad en el puesto a cambio de cierta aquiescencia con el entorno político, y el predominio de los derechos individuales del trabajador sobre los colectivos, no crearon un escenario muy proclive para la identificación de la clase trabajadora con la acción colectiva. Las movilizaciones se percibían como acciones políticas, con consecuencias y características políticas, más que económicas o laborales. La relación entre los trabajadores y el movimiento sindical durante el franquismo estuvo siempre atravesada, aun en el ámbito laboral, por la esfera política.

El inicio de la transición democrática no varía este supuesto. Los sindicatos mayoritarios, en un lógico interés por legitimar y consolidar el nuevo régimen de libertades, siguen y acatan la actuación de sus partidos políticos de referencia (PSOE y PCE). Los años inmediatamente posteriores a la muerte de Franco, caracterizados por un alto grado de movilizaciones y protestas, se explican por el apoyo explícito de los trabajadores al sistema democrático y por las expectativas generadas en torno al nuevo sistema de relaciones laborales. La dinámica propia de la clandestinidad: movilizaciones y acciones sin organización ${ }^{10}$ (Fishman, 1984), fue la tónica dominante de las acciones en estos primeros años de la transición. De ahí que tales síntomas de acción colectiva: huelgas, manifestaciones, afiliación sindical masiva, hayan de ser relativizados y reubicados en un contexto definido por las prioridades políticas.

10. FISHMAN, R.: «El movimiento obrero en la transicion: objetivos políticos y organizativos». REIS, núm. 26, 1984, p. 61-112. 
Ahora bien, las organizaciones sindicales se equivocaron al pensar que tales muestras de apoyo al movimiento sindical podían ser asimiladas con una base de representación fuerte y estable. Muy al contrario, el nivel de compromiso con el movimiento sindical se mostró mucho más débil y contingente de lo que los líderes sindicales habían pensado. Una vez que la transición política se refrenda con la Constitución, la legalización de los partidos y cierta normalización de la vida política, la identificación primaria que el trabajador estaba dispuesto a mantener con respecto a las organizaciones sindicales había llegado a su límite. Ni la convicción ideológica — sólo una minoría participó activamente en la lucha contra el régimen franquista-, ni mucho menos una posible consolidación organizativa de los sindicatos aparecían como medios que frenaran la desmovilización.

En esta situación, los primeros años de la década de los ochenta vienen marcados por el proceso de concertación y el descenso de la conflictividad. El proceso de concertación en el que de manera desigual participaron las principales organizaciones sindicales, afectó a la desmovilización en tanto en cuanto las cúpulas sindicales controlaron en buena medida las acciones en los niveles inferiores de la organización, pero este hecho no provocó, en sí mismo, la desmovilización de una clase trabajadora supuestamente radical y reformista. El apoyo a los procesos de concertación por parte de los trabajadores muestra un clima de relaciones laborales en la base más presidido por el consenso que por el conflicto. Creo que la verdadera naturaleza del problema de las relaciones entre movimiento sindical y trabajadores fue la dependencia de los sindicatos con respecto a los partidos políticos y, como derivación, el excesivo peso de lo político, tanto en las propias organizaciones sindicales como en su estrategia de acción en la esfera laboral. La consecuencia, reforzada a través del proceso de concertación, fue el alejamiento de las organizaciones sindicales del centro de trabajo, con la consiguiente pérdida de representación entre los trabajadores.

Desde el prisma de las organizaciones, la opción de la esfera pública en detrimento de la acción sindical estuvo constreñida política, económica y organizativamente. La necesidad de consolidar sus organizaciones, el nivel de enfrentamiento político-ideológico entre las distintas opciones y las consecuencias de una crisis económica de todavía imprevisibles resultados, trasladó la acción sindical al terreno de la política, relegando a un segundo plano la acción sindical en el centro de trabajo.

En la necesaria conjunción para el éxito de una organización de interés de la lógica de la influencia o relaciones con el Estado y el resto de los agentes sociales, y la lógica de los miembros, relaciones con sus representados, el desarrollo del movimiento sindical a lo largo del periodo de transición y consolidación democrática, primó sistemáticamente la lógica de la influencia en detrimento de la lógica de los miembros. La separación de los sindicatos del centro de trabajo, la división sindical y los efectos visibles de la crisis económica y crisis de empleo, impidió el refuerzo de los vínculos entre el movimiento sindical y los trabajadores. Desde 1980 hasta 1985 las centrales sindicales pierden la mayor parte de los afiliados; sólo el núcleo más ideologizado per- 
maneció afiliado, ya que la identificación con la organización, vía ideología, no se vio afectada por las estrategias sindicales ${ }^{11}$.

El marco legal negociado durante esos años favoreció la lógica de la influencia en detrimento de la lógica de los miembros, al primar la representatividad como fundamental y casi único baremo de la presencia y la fuerza sindical. Bien es verdad que la consolidación de las cúpulas sindicales y un grado considerable de presencia pública era condición indispensable para su presencia en cualquier ámbito, pero al reforzar la lógica de la influencia descuidaron una estrategia tendente a la acción sindical micro. La segmentación del mercado de trabajo no hizo sino agravar el desfase de representación, por cuanto los sindicatos, requeridos como organizaciones para la defensa de la globalidad de la clase trabajadora, se vieron impotentes para derivar recursos que compensaran los efectos de la crisis en relación con la segregación y la diferenciación de los trabajadores.

En esos años, el movimiento sindical mayoritario se mantuvo para y gracias a la presencia pública. Ya fuera en términos de consenso y aceptación de la política de concertación (UGT), ya en forma de oposición al modelo de pactos y al poder político (CC.OO.), ambas opciones mayoritarias centraron sus estrategias y recursos en la acción sindical macro. En la confranza que una vez consolidada su presencia e influencia en el ámbito político, la representación y el apoyo de la base vendrían como consecuencias naturales, los sindicatos no calcularon la retirada de la base y el alejamiento efecto de los excesos de dicha estrategia.

La etapa de concertación permitió a los sindicatos mayoritarios un desarrollo notable de sus organizaciones, mayor presencia oficial y pública y una representación sindical en las empresas muy importante ${ }^{12}$. Sin embargo, no fue posible la necesaria imbricación entre acción sindical representativa a nivel social y acción sindical en la empresa. El apoyo de los trabajadores hacia los sindicatos (al nivel más general) no pudo traducirse en un grado más alto de vinculación con las organizaciones sindicales.

La mitad de los ańos ochenta marca un cambio significativo en la estrategia del movimiento sindical de clase. El compromiso de moderación y apoyo a la política económica del Gobierno por parte de UGT se rompe cuando la central sindical percibe que los signos de recuperación económica, que empiezan a hacerse visibles alrededor de 1985, no se traducen en una mejora de las condiciones para los trabajadores. El modelo de concertación seguido desde la transición se rompe definitivamente cuando los sindicatos se niegan a aplazar por más tiempo las expectativas generadas en torno al cambio económico.

11. BouzA, F., ibídem, p. I y BouzA, F.: Perfil, Actitudes y Demandas del delegado y afiliado a UGT. Madrid, Fundación Largo Caballero, 1989.

12. En las sucesivas elecciones sindicales, los trabajadores han respaldado a los dos sindicatos de clase mayoritarios. En las elecciones sindicales de 1990, casi el ochenta por ciento $-79,02 \%$ - de los delegados elegidos pertenecían a CC.OO. y UGT). Fuente: BOE núm. 273 del 14 de noviembre de 1991. 
UGT y CC.OO. dan por cerrado el período de concertación vía pactos globales y comienzan a reclamar un nuevo espacio de representación más alejado del ámbito político en el que habían estado durante los años anteriores.

El cambio se explicita, no en un paso de la esfera macro a la micro de representación, sino en una transformación del espacio de intervención de los sindicatos. Frente a la negociación al más alto nivel, se pasa a la negociación por las vías tradicionales; presión ante el Gobierno y retorno a la negociación colectiva.

De forma paralela e interrelacionada, comienza a aparecer en las declaraciones sindicales un significativo interés, a nivel programático, por el aumento de la afiliación y la consolidación de las estructuras de representación en los niveles inferiores de la organización. Sin un espacio claro de intervención en la esfera de los asuntos públicos, y con una base de representación fuera de la influencia directa del sindicato, el área de dominio sindical más propicio parece el centro de trabajo.

Al tiempo, UGT se distancia ideológicamente de su partido de referencia por el solapamiento entre partido y Gobierno. CC.OO., por su parte, consigue cierto alejamiento por la propia debilidad manifiesta y divisiones internas del PCE. La consecuencia de la independencia política y de la opción ugetista por el retorno a la presión como método de acción sindical, se manifiesta en un acercamiento estratégico de ambas centrales que culminará con la unidad de acción en la huelga del 14 de diciembre de 1988 .

La receptividad de los trabajadores ante estos cambios se pone de manifiesto tanto en términos de apoyo a las movilizaciones sindicales como, desde otra óptica, en el comienzo del cambio de tendencia en la afiliación que, a partir de 1986, comienza una tendencia ligeramente ascendente. Ahora bien, ambos fenómenos, aunque coincidentes en el tiempo y relacionados, pertenecen a dos campos de significación distintos.

Por un lado, no conviene confundir los grados de compromiso con la organización que suponen las movilizaciones en relación con la afiliación. Una cuestión es la solidaridad concreta y coyuntural que significa una movilización, y otra bien distinta el nivel de vinculación requerido para la pertenencia a un sindicato, en el que además de solidaridad, la relación implica cierta estabilidad, y por tanto ciertas contrapartidas no coyunturales. El éxito de la huelga general ha de ser entendido en la primera de estas lógicas. Es el respaldo de los trabajadores al sindicalismo como organización social de defensa de la clase trabajadora como un todo, desde la lógica de la influencia. Pero como he venido argumentando hasta ahora, este tipo de apoyos explícitos no genera un compromiso de tipo afiliativo estable. La vinculación sindical más estrecha se logra, en las condiciones de las sociedades complejas, a través de la puesta en escena de intereses objetivos, de carácter racional y orientados a la mejora de las condiciones, no de grupo, sino de un cariz más individual.

En diciembre de 1988 el movimiento sindical consigue recuperar la confianza y el apoyo de los trabajadores, que había quedado muy erosionada por las cuestiones ya analizadas: excesiva presencia en la esfera de los asuntos públi- 
cos, divisiones ideológicas intersindicales y la dependencia de los partidos. En este sentido, el giro que supone la nueva estrategia elaborada a partir de ese año confirma y devuelve la legitimidad al movimiento sindical por parte de la mayoría de los trabajadores. En realidad, la necesaria presencia del sindicato como organización de interés para la promoción y la defensa de los intereses generales del conjunto de los trabajadores es, como he comentado, condición necesaria para lograr un grado de legitimidad y presencia notables entre las bases potenciales. Sin embargo, la lógica de la afiliación se basa en otras condiciones. De hecho, el rebrote afiliativo que consiguen los sindicatos mayoritarios en estos años no debe ser atribuido, al menos como única causa explicativa, al apoyo recibido en términos sociales, por las razones comentadas de distintos niveles de compromiso y contrapartidas requeridos en una y otra situación. La explicación para el aumento de la afiliación reside más en aspectos de promoción afiliativa de los sindicatos, en extensión de su presencia en ámbitos tradicionalmente no sindicalizados y en un reforzamiento y una derivación de recursos hacia la acción sindical en el centro de trabajo. La confirmación de la LOLS de la representación estrictamente sindical en las empresas a través de las secciones sindicales, con el consiguiente refuerzo de las estructuras micro, la creación, primero por parte de UG'T y después seguida por el resto de las centrales de los servicios sindicales, son signos evidentes de la transformación en la dirección de un mayor y creciente interés por conectar a nivel concreto con los trabajadores. Los sindicatos han aprendido de la experiencia de la transición; el compromiso no se mantiene por la apelación exclusiva a la solidaridad de clase, hay que poner en juego otros recursos de acción colectiva adaptados a necesidades más concretas e inmediatas de los trabajadores. Por primera vez en diez años, se trata de combinar la doble lógica de la influencia y de los miembros, en el intento de lograr un movimiento sindical representativo pero también representante de la clase trabajadora.

He tratado de mostrar cómo el escenario postcrisis de las economías capitalistas, las estrategias sindicales y las circunstancias históricas del franquismo y la transición democrática, han afectado conjunta y negativamente al desarrollo de la afiliación sindical en España. Quedan por ver los retos a los que se enfrentará el movimiento sindical en los próximos años. A esta cuestión se dedica el último apartado.

\section{IV}

El desarrollo futuro del sindicalismo en nuestro país dependerá no tanto de la dirección que tomen los cambios en la estructura ocupacional (estas transformaciones por el hecho de ser estructurales no van a variar en lo sustantivo en un futuro próximo), sino de la estrategia sindical en lo atinente a la resolución de la tensión entre las dos lógicas comentadas; lógica de los miembros y lógica de la influencia.

Por un lado, la imagen de eficacia se construye a través de la presencia efectiva de los sindicatos en la promoción y en la defensa de los intereses inme- 
diatos de los trabajadores, nunca mediante el sindicalismo solidario. Por otro, el sindicato como organización social vela por los intereses generales de la «clase trabajadora», pero las tendencias desagregadoras no permiten en este nivel una mayor concreción que no sea la defensa de los intereses concretos de los más desfavorecidos, y en especial aquellos que se encuentran fuera del mercado de trabajo (jóvenes, desempleados, jubilados, precarios).

La solución pasa por un punto intermedio que resuelva la tensión existente entre las dos lógicas para convertirlas en complementarias. Si definitivamente el movimiento sindical español de clase (el mayoritario) opta únicamente por el sindicalismo solidario, su presencia social quedará asegurada, pero no podrá conseguir un grado aceptable de compromiso con la organización (vía afiliación) de parte de los trabajadores. Sin embargo, una actitud que sólo contemple una acción sindical volcada en la representación corre el peligro de olvidar a los colectivos más desprotegidos en el mercado de trabajo, ya que son los que menores posibilidades tienen de acceder a la organización por la vía de la afiliación. Si estos colectivos, por mor de su situación ocupacional, no pueden pertenecer al sindicato (sin intereses y sobre todo sin capacidad para defenderlos a través de la acción colectiva), y si el movimiento sindical de clase opta por el sindicalismo de representación, el resultado es la ausencia de cobertura de representación y defensa de estos colectivos por parte de los sindicatos. Es por ello que en situaciones de crisis resulta extremadamente difícil para el sindicalismo de clase conjugar las dos facetas de la acción sindical.

La desventaja comparativa del movimiento sindical español con respecto al europeo se basa, además de las específicas condiciones que han afectado genuinamente el desarrollo de la acción sindical en nuestro país, a un simple desfase temporal. Los más de cuarenta años de retraso de nuestro país en la consolidación de un régimen liberal democrático, impidieron que el movimiento sindical se beneficiara de las condiciones favorables de crecimiento que estaban afectando al resto de los movimientos sindicales europeos.

La aceleración del cambio en la última década da cuenta de un progresivo acercamiento en los estándares sociales a la comunidad europea. El movimiento sindical, siempre que las condiciones internas sean favorables, responderá con un paulatino acercamiento a la realidad sindical de los países del entorno. Tal evolución afectará a todos los órdenes; consolidación organizativa de las centrales sindicales, mayor ajuste, transparencia y frabilidad de las cifras de afiliación, adaptación creciente de la composición afiliativa a la realidad productiva (más mujeres, más trabajadores no manuales), más recursos financieros, etc. Este desarrollo, contemplado en una perspectiva a medio plazo, tendrá que acompañarse necesariamente con cierta direccionalidad en las transformaciones internas: crecimiento del empleo, cierta estabilidad del mercado de trabajo, descenso del enfrentamiento político - tanto de sindicatos y gobierno como de las relaciones intersindicales-y adecuación de las estructuras del sindicato a una realidad dominada por los objetivos concretos de los trabajadores.

Lo que parece claro es que el movimiento sindical no podrá mantenerse en las sociedades complejas sobre la base de una solidaridad difusa, irreal y fuerte- 
mente anclada en lo ideológico. La imagen del sindicalismo como organización de interés de la clase trabajadora ha de seguir manteniéndose en el plano más superestructural. En la realidad cotidiana ha de ser complementada por acciones concretas adaptadas a la diversidad del conglomerado clase trabajadora. La solidaridad intraclasista se difumina en la multiplicidad de situaciones a que están sujetos los miembros de cada clase en la estructura laboral y ocupacional. Si la identidad de clase se ha erosionado debido a los cambios estructurales el movimiento sindical, no puede apelar por más tiempo a una solidaridad clasista de difícil ubicación. En su lugar: la estrategia ha de estar centrada en el individuo trabajador más que en la clase como un todo indivisible y apelable bajo el lema de la igualdad. Aun en condiciones favorables, la afiliación sindical implica un compromiso que muchos, de cualquier manera, no estarán dispuestos a asumir o en el que no se encontrarán contrapartidas claras.

Por último, los retos del sindicalismo ante la unión europea son de un cariz apreciable. En unos años, la consistencia del Estado nación que durante siglos ha sido el soporte de la acción política, habrá de verse modificado por la entrada en juego de una entidad supranacional. De cara al movimiento sindical, la articulación de ambas lógicas entrará en una fase de reubicación y discusión. Si dentro de los países los problemas de agregación ya son de considerable factura, pueden imaginarse las dificultades cuando éstos se trasladen a un escenario de orden superior. El término solidaridad todavía se hará más difuso e inestable, agravado por la descomposición de los regímenes comunistas de la Europa del Este.

La reunificación europea, en términos de representación, probablemente favorecerá al sindicalismo por cuanto el repliegue a espacios y ámbitos de acción cada vez más concretos será consecuencia inevitable por la propia dinámica de extensión de los conflictos. Ahora bien, de manera tentativa, pueden entreverse dos grandes riesgos. Primero, que los movimientos sindicales más consolidados consigan mayores ganancias para sus representados que los movimientos sindicales más débiles; expuestos, en un mercado de competencia, al poder del más fuerte. El otro gran riesgo es la desaparición del carácter social del sindicalismo, diluido en la necesidad de considerar una solidaridad de rango superior al nacional. Aquí se explicita de manera palpable la posible tensión entre representatividad y representación, por cuanto la cultura política de las organizaciones sindicales, fundada en la nación, habrá de verse superada por ese ámbito. Además, el propio balance de fuerzas que el movimiento sindical internacional pueda mantener frente a la lógica capitalista, tendrá importantes consecuencias para el posicionamiento del movimiento sindical europeo como movimiento social y solidario. En este sentido será fundamental el papel que consigan los sindicatos en el nuevo orden social. El extremo de la capacidad de influencia y decisión en los ámbitos sociales y laborales de la Europa unida dará cuenta de la fuerza del sindicalismo como organización de interés de ámbito superior al del Estado nación.

Otra cuestión importante será la capacidad de consenso en el movimiento sindical internacional en el sentido de unificación política. Sólo con observar 
las consecuencias en nuestro país de las diferencias ideológicas de los sindicatos pueden imaginarse los problemas para alcanzar acuerdos que limiten el enfrentamiento ideológico en el sindicalismo europeo. Si la unión orgánica de movimientos sindicales como el francés, el italiano, el holandés o el español se percibe como poco probable en un futuro cercano, las dificultades para lograrlo en un sistema supranacional pueden aumentar exponencialmente. Aun a pesar de todos estos problemas, el conflicto laboral continuará existiendo, y mientras eso ocurra, el movimiento sindical tendrá buenas razones para continuar defendiendo y articulando los intereses de los trabajadores.

\section{Bibliografía}

AGUil.AR, S.; RoCA, J. (1991). «Trabajadores y sindicatos en una sociedad compleja. Las estrategias de los sindicatos españoles durante la transición". Ponencia presentada en el seminario La integración sindical en estructuras sociales complejas. Sevilla: UIMP.

BaIN, G.S. (ed.) (1988). Relaciones Industriales en Gran Bretaña. Madrid: Ministerio de Trabajo y Seguridad Social.

PAYlos, A. (1990). «Ley sindical y sindicato más representativo en España». Politica y Sociedad, núm. 5, p. 23-30.

BELL, D. (1982). El advenimiento de la sociedad postindustrial. Madrid: Alianza Universidad.

BELL, D. (1992). El fin de las ideologias. Madrid: Ministerio de Trabajo y Seguridad Social.

BoUZA, F. (1989). Perfil, Actitudes y Dermandas del delegado y afiliado a UGT. Madrid: Fundación Largo Caballero.

BOUZA, F:; TABOADELA, O. (1994). «La evolución de la afiliación sindical en España y la cultura histórica de los sindicatos». Documentación Social, núm. 94, p. 119 127.

CASAS BAHAMONDE, M.E. (1988). «Representatividad y mayor representatividad de los sindicatos en España. ¿Un modelo en crisis?». Revista del Derecho del Trabaio Civitas, núm. 33, p. 71-85.

Crouch, C. (1982). Trade Unions: The loqic of collective action. Londres: Fontana.

DURÁN LOPEZ, F. (1985). «Sindicatos y salida concertada de la crisis». Papeles de economia española, núm. 22, p. 316-328.

EsCobar MerCado, M. (1991). "Afiliación y movilización en España". Ponencia presentada en el seminario La integración sindical en estructuras sociales complejas. Sevilla: UIMP.

EsCUDERO Rodríguez, M. (1990). La representatividad de los sindicatos en el modelo laboral español. Madrid: Tecnos.

FiSHMAN, R. (1984). "El movimiento obrero en la transición: objetivos políticos y organizativos». REIS, núm. 26, p. 61-112.

JORDANA, J. (1989). «Del 14-D al sindicalismo de los años noventa. Una aproximación a la política de los sindicatos en España». Sociologia del Trabajo, núm. 8, p. 31-58.

Miguélez. LOBO, F. (1985). «Sindicalismo y conflicto social en la España de la transición». Mientras Tanto, núm. 24, p. 35-54.

OCDE (1991). Perspectives de l'emploi. París: OCDE.

PARAMIO, L. (1988). Tras el diluvio. La izquierda ante el fin de siglo. Madrid: Siglo XXI. 
Pérez Díaz, V. (1991). «La emergencia de la España democrática. La "invención" de una tradición y la dudosa institucionalización de una democracia". Claves de Razón Práctica, núm. 13, p. 62-80.

POOLE, M. (1990). Teorias del sindicalismo. Una sociología de las relaciones industriales. Madrid: Ministerio de Trabajo y Seguridad Social.

REGINI, M. (1981). «La crisis de representatividad de los sindicatos de clase». Sociología del Trabajo, núm. 6, p. 51-67.

TABOADELA, O. (1993). "Clases sociales y acción colectiva». REIS, núm. 63, p. 71 97.

VISSER, J. (1988). «Trade unionism in Western Europe: present situation and prospects". Labour and Society. Vol. 13, núm. 2, p. 125-182.

VISSER, J. (1989). European trade unions in figures. Deventer: Kluwer Publ.

WRIGHT, E.O.; KWANG-YEONG, S. (1987). «Temporality class structure and class consciousness: A comparative analysis of the effects of class trayectory and class structure on class consciousness in Sweden and the Unites States». Mimeo, Department of Sociology. Madison, University of Wisconsin.

ZARAGOZA, A. (ed.) (1988). Pactos sociales, sindicatos y patronal en España. Madrid: Siglo XXI. 